\title{
An Analysis of the Academic Performance of Candidates by Gender in SSCE (NECO).
}

\author{
Victoria Adah, ${ }^{1 *}$ Bashiru Omeiza Sule ${ }^{2}$ \\ 1. Department of Mathematics/Statistics/Computer Science, College of science, University of Agriculture, \\ P.M.B. 2373, Makurdi, Nigeria \\ 2. Department of Mathematical Sciences, Faculty of Natural Science, Kogi State University, P.M.B. 1008, \\ Anyigba, Kogi State, Nigeria \\ *E-mail of the corresponding author: adahvictoria14@yahoo.com.
}

\begin{abstract}
The study seeks to determine the relationship between gender and students' academic performance in SSCE (NECO). The purpose of the research was to determine if gender is independent of academic performance in SSCE (NECO) using the chi-square test and odds ratio. The data used for the study was collected from the Annual Statistical Abstract. The Pearson Chi-Square statistic, $\chi^{2}=41.866$, and $p<0.05$ indicates that the there is an association between gender and students' academic performance. The odds ratio shows that the odds of a female student having a minimum of five credit including English and Mathematics is 0.684 as likely for the odds of a male student. Conclusively female candidates seem to be less likely in having a minimum of five credit including English and Mathematics since the odds ratio is less than 1.0.
\end{abstract}

Keywords: Academic, chi-square, gender, NECO, odds-ratio, performance, relationship

DOI: $10.7176 / \mathrm{MTM} / 9-2-01$

\section{Introduction}

Examinations in schools in Nigerian areas far back as the arrival of education. The 1887 Education policy made provision for public examinations in schools. Thus the National Procedure for Education stipulated that all secondary schools should be such that their programmes meet the requirements of examinations being conducted for the Senior School Certificate Examination (SSCE). The method of grading candidates' scores in the examinations was such that the distinction grades were denoted by A1 to B3, C4 to C6for credit grades, D7 and E8 for the pass grade while the failure is F9.However, that the distinction and credit grades are the only mandatory qualifications for admissions into universities in Nigeria and candidates must have at least credit in five subjects including English Language in order to qualify for admission (Adeyemi, 2008).

The West African Examination Council (WAEC) for a number of decades has been the only examination body in this country especially for ordinary level of examination. The failure rates especially in Mathematics and English language have been a reason for concern. There has also been criticism against National Examination Council (NECO). Some say their questions are more tasking than that of WAEC, while some says WAEC has more standard than NECO. Presently some universities who once rejected NECO results for admission now accept it. Many private owned secondary schools now register their students for NECO. One of the reasons could be that WAEC and NECO have the same syllabus and each of them has a regulatory body hence the two examination body are equivalent (Ali and Enyo, 2016).

Examination malpractices and mass failure has been the order of the day in public examinations in Nigeria, particularly the Secondary School Certificate Examinations. The recent evaluation procedure is not implemented effectively and the situation has deteriorated by lack of capable and committed supervision and monitoring of education process (Moyinoluwa, 2015). In any case, since the senior secondary school certificate examinations were set, conducted and scored by bodies external to the schools, it is possible that some of the viruses that account for poor performance could be related to the external examination bodies. Several factors were observed to be responsible for students' mass failure in public examinations; some blamed the home, society and parents for failure to inculcate discipline and learning habits in their children. Others blamed the Government for failure to provide human and material resources to facilitate good teaching and learning, some blamed the teachers for failure to inculcate the necessary knowledge, skills and behavior to students and also the students themselves for refusal to learn, while majority of others blamed WAEC or NECO for their failure to measure adequately the knowledge, skills and behavior learned by students. Whatever the factors are, there is clearly the need to get 
something done urgently in order to create the type of assessment and examination procedures that is deserved, as it may be a silent cause for the poor performance level in the SSCE. The basic qualification for admission into any higher institution in Nigeria is the Senior School Certificate issued by the WAEC, NECO and / or NABTEB. At the end of secondary school education, students are expected to sit for examinations conducted by the West African Examinations Council (WAEC), National Examinations Council (NECO) and National Business and Technical Examination Board (NABTEB) (Moyinoluwa, 2015).

In Nigeria, two examining bodies WAEC and NECO are responsible for the award of the Senior Secondary School Leaving Certificate (SSSC) (Bandele and Adewale, 2013).

As a result of this importance, English Language is taught at all levels of education in Nigeria as a second language. Nigerian students have to compete with English Language at all levels. For any student to be considered as having passed the Senior School Certificate examination (SSCE), he must have passed English Language and Mathematics at credit level. His strength of competency in English Language is evaluated, especially when it has to do with sitting and passing examination. The Nigerian student is taught the language as a subject from the first year in pre-primary or primary school. He is taught the language for six years in the primary school, six years in the secondary school and one year in the tertiary institution (Popoola and Olubunmi, 2013).

English language is an official language in Nigeria and whatsoever you want to do you have to communicate in English; consequently you cannot escape English language throughout your lives in your carrier of choice. If you want to study engineering, medicine, accounting, economics as well as other formal disciplines in the university English language is a pre-requisite to gaining admission into the university (Muhammad et al 2018)

Mathematics is enshrined in the National Policy on Education (NPE) as a core and compulsory subject for all primary and post-primary school students in Nigeria (Federal Republic of Nigeria (FRN), 2004). This is largely because of the indispensable role it plays in the advancement of science and technology of any nation. This has led to its inclusion as a pre-requisite for admission to science-based courses in the institutions of higher learning in Nigeria.(Matawal, 2013)

The importance of English Language and Mathematics as pre-requisite subjects to gain admission into higher institutions of learning in Nigeria and some West African Countries such as Ghana, The Gambia, Sierra Leone and Liberia (These countries have the same colonial origin and jointly established the WAEC) has made the two subjects mandatory to be passed at credit level by secondary schools students in public examinations. A credit level in either of the subjects has been used as one of the criteria for measuring and establishing the brilliancy of a particular candidate in the Nigerian setting. The poor performance of secondary school students in SSCE in English Language and Mathematics had made it difficult for majority of students to gain admission into higher institutions of learning in recent times (Adepoju, 2011)

Gender is one factors also mentioned in literature to have considerable effects on students' academic performances especially in science subjects. Gender is the range of physical, biological, mental and behavioral characteristics pertaining to and differentiating between the feminine and masculine population(Unity and Igbudu, 2015; Joseph et. al 2015).

Olasehinde and Olatoye (2014) compared male and female senior secondary school students' learning outcomes in science in Katsina State, Nigeria, the study reveals that though there is no significant difference in the mean scores of male and female students in science achievement,female students performed better than the male counterparts.

Unity and Igbudu, (2015), studied the influence of gender in students' academic achievement in government subject in secondary schools in Oredo Local Government Area of Edo State. The study revealed there exist a difference in academic achievement, though the differences are insignificant in some cases.

The importance of examining performance in relation to gender is based primarily on the socio-cultural differences between girls and boys.

\section{Contingency Tables}

Let $\mathrm{X}$ and $\mathrm{Y}$ denote two categorical response variables, $\mathrm{X}$ with $\mathrm{I}$ categories and $\mathrm{Y}$ with $\mathrm{J}$ categories. Classifications of subjects on both variables have IJ possible combinations. A rectangular table having I rows for categories of $\mathrm{X}$ and $\mathrm{J}$ columns for categories of Y displays this distribution. The cells of the table represent the IJ possible outcomes. When the cells contain frequency counts of outcomes for a sample, the table is called a 
contingency table, a term introduced by Karl Pearson 1904. Another name is cross-classification table. A contingency table with I rows and J columns is called an I x J (or I-by-J)table (Agresti, 2002; Agresti, 2007).).In this research paper a two by two contingency table was employed as shown in table 1.

Where,

$\mathrm{a}_{1}$ : number of individual who are in type I in category I and type I in category II

$a_{2}$ : number of individual who are in type I in category I and type II in category II

$b_{1}$ :number of individual who are in type II in category I and type I in category II

$b_{2}$ :number of individual who are in type II in category I and type II in category II

$\mathrm{N}$ : total number of individuals.

Category I:Candidates with Minim of 5 Credits including English Language \& Mathematics. (Type I - Yes/ Type II -No)

Category II: Gender (Type I - Male / Type II - Female)

\subsection{Specification}

$\mathrm{P}$ is the probability of an event

Event: A candidate having a minimum of five credit including English and Mathematics.

$\mathrm{P}(\mathrm{A})$ : The probability of a male having a minimum of five credit including English and Mathematics.

$\mathrm{P}(\mathrm{B})$ : The probability of a female having a minimum of five credit including English and Mathematics

\subsection{Test of independence}

A test of Independence is a chi-square technique used to determine whether two characteristics are related or independent. The test enables us to explain whether or not two attributes are associated. In other words, it is used to estimate the likelihood that some factor other than chance accounts for the observed relationship (Onchiri, 2013).

Chi-square, symbolized as $\chi^{2}$, is a non-parametric test of significance appropriate when the data is in form of frequency counts occurring in two or more mutually exclusive categories. A Chi-square test compares proportions actually observed in a study with the expected to establish if they are significantly different. The Chi-square value increases as the difference between observed and expected increase. Whether the calculated Chi-square value is significant is determined by comparing it with the value from table. If the calculated value exceeds the table value, the difference between the observed and expected frequencies is taken as significant otherwise it is considered insignificant

\subsubsection{Yates's correction for continuity}

Using the chi-squared distribution to interpret Pearson's chi-squared statistic requires one to assume that the discrete probability of observed binomial frequencies in the table can be approximated by the continuous chisquared distribution. This assumption is not quite correct, and introduces some error.

To reduce the error in approximation, Frank Yates suggested a correction for continuity that adjusts the formula for Pearson's chi-squared test by subtracting 0.5 from the difference between each observed value and its expected value in a $2 \times 2$ contingency table. This reduces the chi-squared value obtained and thus increases its $p$ value.

\subsection{Procedures for Chi-Square test}

- $\quad$ From a random sample, we observe the number $O_{i}$ falling into the $i^{\text {th }}$ of $k$ categories.

- We calculate the expected numbers $E_{i}$, in each category $i$, assuming the theory or null hypothesis.

- We then test if the differences $O_{i}-E_{i}$ large enough to be inconsistent with the theory

The Chi-Square Statistic, G 


$$
\begin{gathered}
G=\Sigma_{i=1}^{k} \frac{\left(O_{i}-E_{i}\right)^{2}}{E_{i}} \\
\text { where } E_{i}=\frac{n_{i} m_{i}}{N} \text { and } n_{i} m_{i}, i=1,2
\end{gathered}
$$

For a large sample size and assuming the theory (null hypothesis) is true $G$ has an approximate Chi-square distribution with $(\mathrm{k}-1)$ degrees of freedom.

$$
G \approx \chi_{k-1}^{2}
$$

\subsection{Odds and probability}

The odds of an event and the odds ratio of events are very common.

The odds of an event is define as

$$
\text { Odds }(\text { event })=\frac{P(\text { event })}{P(\text { not event })}=\frac{P(\text { event })}{1-P(\text { event })}
$$

Thus the odd of event A is given by: $\frac{P(A)}{1-P(A)}$

\subsection{Odds Ratio.}

This odd ratio terminology is the easiest to understand when we are dealing with a special case in which both $\mathrm{X}$ and $\mathrm{Y}$ are dichotomous. When they are both dichotomous, the odds ratio is the probability that $\mathrm{Y}$ is 1 when $\mathrm{X}$ is 1 compared to the probability that $\mathrm{Y}$ is 1 when $\mathrm{X}$ is 0

The odds ratio (OR) is by definition, the ratio of two odds:

$O R_{A V S B}=\frac{\operatorname{Odds}(\mathrm{A})}{\operatorname{Odds}(\mathrm{B})}=\frac{\frac{P(A)}{1-P(A)}}{\frac{P(B)}{1-P(B)}}$

It is convenient to model probabilities on the log-odds scale. The log-odds (LO), also known as the logit,It is

defined as: $\operatorname{logit}(\mathrm{A})=\log _{\mathrm{e}} \operatorname{Odds}(\mathrm{A})=\log _{\mathrm{e}}\left(\frac{\mathrm{P}(\mathrm{A})}{1-\mathrm{P}(\mathrm{A})}\right)$

An odds ratio of 0.5 indicates that $Y=1$ is half as likely with an increase of $X$ by one unit (so there is a negative relationship between $\mathrm{X}$ and $\mathrm{Y}$ ). An odds ratio of 1.0 indicates there is no relationship between $\mathrm{X}$ and $\mathrm{Y}$. The odds ratio can equal any nonnegative number $1<O R<\infty$. Values of $\mathrm{OR}$ farther from 1.0 in a given direction represent stronger association. Two values represent the same association, but in opposite directions, when one is the inverse of the other. For instance, when OR $=0.25$, the odds of success in row 1 are 0.25 times the odds in row 2 , or equivalently, the odds of success in row 2 are $1 / 0.25=4.0$ times the odds in row 1 . When the order of the rows is reversed or the order of the columns is reversed, the new value for OR is the inverse of the original value. It is convenient to use $\log (\mathrm{OR})=0$. Independence corresponds to $\log (\mathrm{OR})=0$. The $\log$ odds ratio is symmetric about this value reversal of rows or of columns results in a change in its sign. Two values for log (OR) that are the same except for sign, such as $\log 4=1.39$ and $\log 0.25=-1.39$, represent the same strength of association. Ratios less than 1.0 indicate that being in the exposed /selected group decreases the odds/risk of experiencing the outcome, whereas ratios greater than 1.0 indicate that being in the exposed/selected group increases the odds/risk of experiencing the outcome (Osborne, 2006).

\subsubsection{Confidence interval for Odds ratio}

The general idea is to select all cases in the population and a simple random sample of non-cases (controls). The cross-tabulated data looks like this.

Case control studies cannot calculate incidence or prevalence. They can, however, calculate exposure odds ratios:

$$
\widehat{\mathrm{O} R}=\frac{\mathrm{A}_{1} \mathrm{~B}_{2}}{\mathrm{~A}_{2} \mathrm{~B}_{1}}
$$


This statistic, which is just the cross-product ratio of the entries in the 2-by-2 table, is an estimate of the relative incidence (relative risk) of the outcome associated with exposure (assuming data are error-free).

The confidence interval for the $O R$ parameter is

$$
e^{\ln \hat{O} R \pm z \cdot S E_{\ln \hat{O} R}}
$$

whereeis the base on the natural logarithms $(e \approx 2.71828 \ldots), z$ is a Standard Normal deviate corresponding to the level of confidence $(z=1.645$ for $90 \%$ confidence, $z=1.96$ for $95 \%$ confidence, and $z=2.576$ for $99 \%$ confidence), and

$$
S E_{\text {lnôR }}=\sqrt{\frac{1}{a_{1}}+\frac{1}{a_{2}}+\frac{1}{b_{1}}+\frac{1}{b_{2}}}
$$

A test of $H_{0}: O R=1$ is calculated with a chi-square statistic or Fisher's test, depending on the size of the sample.

The odds ratio does not change value when the orientation of the table reverses so that the rows become the columns and the columns become the rows. This is clear from the symmetric form .It is unnecessary to identify one classification as the response variable in order to use OR.

\section{Results}

Result based on the analysis of data collected from the Annual Statistical Abstract, is presented in table 2,3 and 4 . The statistical software employed for this analysis is the SPSS version 20.0

\subsection{Discussions}

Table 2 shows the observed and expected values, the expected number of candidates who are male/ female and have minimum of five credit including English and Mathematics are 681.7 and 475.3respectively. Candidates who do not have minimum of five credit including English and Mathematics have an expected number of 62432.3 for male and for 43530.7 female respectively. The residual is the difference between the actual frequency and the expected frequency. When converted to a $\mathrm{z}$-score, the standardized residual (4.9) was greater than the critical value (1.96), supporting a specific finding that among the student who had minimum of five credit including English language and mathematics, there were more who were female than would be expected.

Table 3 tells us that " 0 cells have expected count less than 5 and the minimum expected count is 475.31 " hence the sample size requirement for the chi-square test of independence is satisfied. Pearson Chi-Square statistic, $\chi^{2}=$ 41.866, and $\mathrm{p}<0.05$; that is, a very small probability of the observed data under the null hypothesis of no relationship. The null hypothesis is rejected, since $\mathrm{p}<0.05$; this implies significant relationship between gender and performance of the candidates.

Table 4 shows the odds of a male candidate having a minimum of five credit including English and Mathematics is 0.0092 while the odds of a female candidate having a minimum of five credit including English and Mathematics 0.0134 . It can also be seen that the odds ratio is 0.684 which implies that the odds of a female student having a minimum of five credit including English and Mathematics is 0.684 as likely for the odds of a male student.

\section{Conclusion}

The chi-square test for independent indicates that there is a relationship between gender and having a minimum of five credit including English and Mathematics. The odds ratio shows the association between gender and the minimum credit obtained is higher for women compared to men.

\section{References}

Adepoju, T. L.(2011),"A Study of Secondary School Students' Academic Performance at the Senior School Certificate Examinations and Implications for Educational Planning and Policy in Nigeria" An International Multidiscipli, Ethiopia 5(6),314-333

Agresti, A., (2002),"Categorical Data Analysis”, A John Wiley \& sons, Inc., publication. 2nd edition, 36pp.

Agresti, A., (2007).,"An introduction to Categorical Data Analysis", A John Wiley \& sons, Inc. Publication. 2nd edition, 21-30.

Ali, H. O. and Enyo, A. E. (2016),"Correlation Analysis Of Student Achievement in West Africa Examination Council and National Examination Council of Nigeria in Mathematics" JORIND 14(1),1596-8303. 
Bandele, S. O. and Adewale, A. E.(2013)",Comparative Analysis of the Reliability and Validity Coefficients of WAEC, NECO and NABTEB Constructed Mathematics Examination", Journal of Educational and Social Research 3(2),397-400

Joseph , A., John, O., Eric, I., Yusuf, S.., \&Olubunmi, A,(2015),'Effect of Gender on Students' Academic Performance in Computer Studies in Secondary Schools in New Bussa, Borgu Local Government of Niger State",Journal of Education and Practice 6(33)

Kimmick, G.,Gloria Broadwater, G. and Vitolins, M.,(2010),"Hot flashes in Breast Cancer Survivors and an Association with Calcium supplement use ”, International Journal of Women's Health,2 291-294

Matawal, D. B.( 2013),"Analysis Of The Relationship Between Students' Achievements In Mathematics In SSCE And Remedial Sciences Programme, University Of Jos-Nigeria”, Comprehensive Journal Of Educational Research 1(3),42 - 46

Moyinoluwa, T.D.(2015),"Analyzing the Psychometric Properties ofMathematics in Public Examinations in Nigeria. The International Journal of Science and Technoledge" 3(4),286-289.

Muhammad H. A., Ya'u S.,Aliyu U. I, Hassan M. (2018),” Teaching and Learning English Language in Nigerian Schools: Importance and Challenges“,Teacher Education and Curriculum Studies3(1),10-13.

Olasehinde, K. J. and Olatoye, R. A.(2014),"Comparison of Male and Female Senior Secondary School Students'Learning Outcomes in Science in Katsina State, Nigeria" Mediterranean Journal of Social Sciences 5(2), 517- 523

Onchiri, S., (2013),"Conceptual model on application of chi-square test in education and social sciences“",Academic Journals. 8 (15),1231-1241

Osakwe, E.(2011),"A Re-Appraisal of Attitudes and Reactions towards Repentant Examination Cheats. Arts and Social Sciences" Arts and Social Sciences Journal, ASSJ-25

Osborne, J. W., (2006),'Practical Evaluation Research and Evaluation", A peer reviewed electronic journal,11 (7),ISSN1531-7714.

Popoola, L. and Olubunmi, S.(2013),"A Correlated Analysis of Students' SSCE Grade and Performance in first year Use-of-English: A case study of Fountain University, Osogbo",Journal of Languages and Culture, 4(8),50154.

Unity, O. \& Igbudu, U. (2015), "Influence of Gender on Students' Academic Achievement in Government Subject in Public Secondary Schools in Oredo Local Government Area of Edo State, Nigeria", Journal of Educational and Social Research 5(2), 101-106

Table 1: General notation of a $2 \times 2$ contingency table.

\begin{tabular}{|l|c|c|c|}
\hline Category II & $\begin{array}{l}\text { Category I } \\
\text { Type I }\end{array}$ & $\begin{array}{l}\text { Category I } \\
\text { Type II }\end{array}$ & \\
\hline Type I & $a_{1}$ & $b_{1}$ & $n_{1}$ \\
\hline Type II & $a_{2}$ & $b_{2}$ & $n_{2}$ \\
\hline Total & $m_{1}$ & $m_{2}$ & $N$ \\
\hline
\end{tabular}


Table 2 gender * min_of_creditCrosstabulation

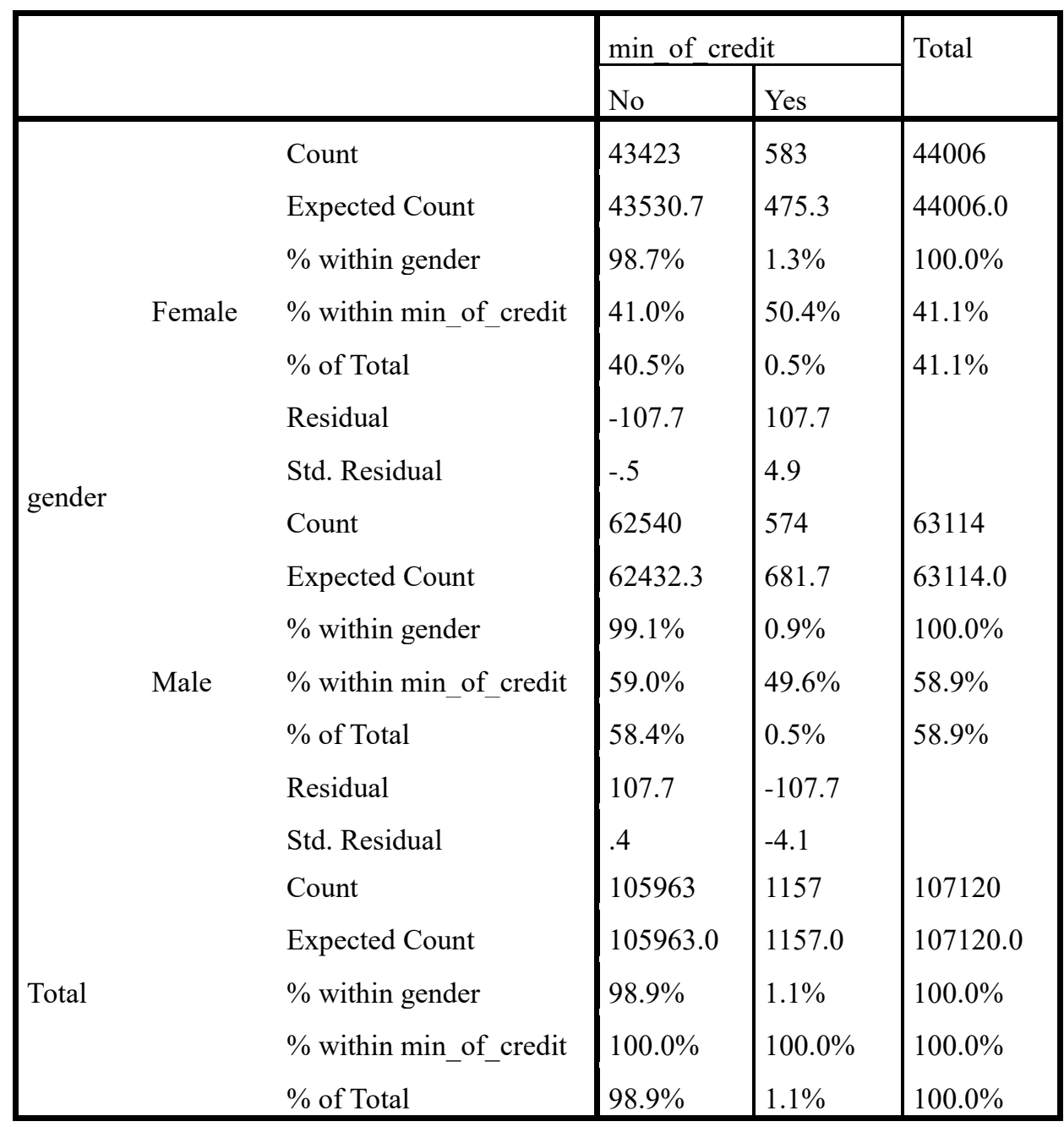

Table 3: Chi-Square Tests

\begin{tabular}{|l|l|l|l|l|l|}
\hline & Value & $\mathrm{df}$ & $\begin{array}{l}\text { Asymp. Sig. (2- } \\
\text { sided) }\end{array}$ & $\begin{array}{l}\text { Exact Sig. (2- } \\
\text { sided) }\end{array}$ & $\begin{array}{l}\text { Exact Sig. (1- } \\
\text { sided) }\end{array}$ \\
\hline Pearson Chi-Square & 41.866 & 1 & .000 & & \\
Continuity Correction & 41.478 & 1 & .000 & & \\
Likelihood Ratio & 41.181 & 1 & .000 & .000 & .000 \\
Fisher's Exact Test & 107120 & & & & \\
N of Valid Cases & & & & \\
\hline
\end{tabular}

a. 0 cells $(0.0 \%)$ have expected count less than 5 . The minimum expected count is 475.31 .

b. Computed only for a $2 \times 2$ table. 
Table 4: Risk Estimate

\begin{tabular}{|l|l|l|l|}
\hline & Value & \multicolumn{2}{|l|}{$95 \%$ Confidence Interval } \\
\cline { 3 - 4 } & & Lower & Upper \\
\hline $\begin{array}{l}\text { Odds ( Male/ Female) } \\
\text { Odds Ratio for factor } \\
\text { ( Female / Male) }\end{array}$ & & & \\
& $(0.0092 / 0.0134)$ & & \\
(Male/ Female) & 0.684 & 0.609 & 0.768 \\
& 1.463 & & \\
For cohort credit = No & & & \\
For cohort credit = Yes & 0.996 & 0.994 & 0.997 \\
N of Valid Cases & 1.457 & 1.299 & 1.634 \\
\hline
\end{tabular}

